${ }^{38}$ Verzijl J.H.M. International Law in Historical Perspective. - Leyden, 1968. - Vol.1. - P. $293 \mathrm{ff}$.

${ }^{39}$ Schindler $D$. Contribution a l'etude des facteurs sociologiques et psychologiges du droit international//RCADI-46. - 1933. - P. 237.

${ }^{40} \mathrm{Cm}$. Stone Ju. Problems Confronting International Law//RCADI-89. 1956. - P. 138.

${ }^{41}$ Blenk-Knocke E. Zu den soziologischen Bedingungen volkerrechtlicher Normenbesorgung. Die Kommunikation von Normen. - Ebelsbach: Verlag Rolfgremer, 1979.
${ }^{42}$ Ibid. - S. 206-212.
${ }^{43}$ Ibid. - S. 84.
4t Ibid. - S. 67, 70, 80 .
45 lbid. - S. 84.
${ }^{46}$ Ibid. - S. 85.
47 Ibid. - S. 95-102.
48 Ibid. - S. 100.

г. Казань.

Cтатья поступила в редакцию в сентабре 1997 года.

\title{
В ЗАЩИТУ МЕЖДУНАРОДНОГО ПРАВА
}

\author{
Ю.A. Решетов*
}

Современное международное право является продуктом длительного развітия отношений между его субъектами.

В нем можно выделить некоторые принципы, институты и нормы старого международного права, которые, несомненно, имели общедемократическую ценность. Однако создание его основных принципов и норм, имеющих основополагающее значение для поддержания международного правопорядка, пришлось на период после второй мировой войны. Решающее влияние на него оказали победа над фашизмом, крах колониальной системы, образование Организации Объединенньх Наций, являющейся ключевьм инструментом мира и международной безопасности. Начавшиеся под влиянием перестройки в Советском Союзе процессы скоро приобрели международное измерение, в результате чего принципы и нормы современ-

*Доктор горидигеских наук, Чрезвыгайный и Полномочный Посол Российской Федерацин в Исландии. Подробнее об авторе см. № 3 нашего журнала 321993 r. 
ного международного права были не только конкретизированы в европейском контексте, но и значительно развиты в новых исторических условиях. Общеевропейский процесс в то же время подтвердил их всеобшую пригодность и непреходящее значение для поддержания мира и безопасности, обеспечения нормальных, лружественных отношений между государствами, продвижения человечества по пути демократии и прогресса.

Несмотря на кровопролитные, часто длящиеся годами конфликты, характерные для последних лет, ничто не способствует общему развитию человечества по восходящей линии в такой мере, как приверженность этим принципам и нормам. Такие принципы, как неприменение силы, нерушимость границ, территориальная целостность, мирное урегулирование споров, суверенное равенство, равноправие, самоопределение, сотрудничество между государствами, права человека, добросовестное выполнение мехдународиых обязательств, лежат в основе международного правопорядка.

Этот международный правопорядок, как и всякий правопорядок, обладает качеством универсальности, в соответствии с которым его субъекты несут равные права и обязанности. Их правовое положение в международной системе обеспечивается этим правопорлдком, в основе которого лежат перечисленные выше принципы.

Такие качества современного международного права, его принципов и норм, которые должны гарантировать поддержание адекватного им правопорядка, были обеспечены в ходе их выработки не в последнюю очередь благодаря тому, что она пронсходила в условияХ двуполярного мира, когда намерения и действия одной стороны, желавшей придать разрабатывающимся правилам проведения выгодный ей характер, нейтрализовалась другой стороной, в результате чего эти принципы и нормы приобретали общедемократический характер. Противостояние двух основных военно-политических блоков, обеспечиваемый им баланс сил приводили и $\mathbf{K}$ тому, что на стадии выполнения основных принципов и норм международного права достигалось в конечном счете следование тем правилам поведения государств, которые были сформулированы в этих принципах и нормах. Долголетняя практика приучала великие державы к пониманию того, что имплементация этих норм на практике соответствовала как интересам всех держав, так и интересам поддержания стабильности и миропорядка в мировом масштабе.

Коренные перемены в международных отношениях, последовавшие вслед за историческими процессами в нашей стране, изменили это положение. С одной стороны, произошло оздоровление международной обстановки, большой вклад в которое внесла Россия, иачалось строительство нового мпропорядка. В советские времена наши представители на международных форумах способствовали 
тому, чтобы разрабатываемые нормы и принципы обладали качествами и параметрами, обеспечивающими их общедемократическое содержание. Однако при их практическом выполнении именно эти качества и параметры сплошь и рядом выхолашивались вследствие настроений руководителей страны, что приводило к авантюрам во внешней политике и невыполнению взятых на себя обязательств, в частности по вопросам прав человека, - во внутренней.

$\mathrm{K}$ тому же вследствие ослабления международных позиций России по сравнению с Советским Союзом, и в первую очередь уменьшения ее военной мощи, ликвидации Варшавского договора, вывода наших войск с территории Центральной и Восточной Европы, у другой стороны усилилось искушение действовать в международных делах исходя в первую очередь из своих эгоистических интересов и пренебрегал нормами и принципами общего международного права. Это прежде всего относится к США, которые и ранее многократно проявляли волюптаристский подход к международному праву, сдерживаемый, однако, во мнопих случалх усилиями восточного блока. Теперь же влилтельные круги в этой ведущей западной стране, видимо, решили, что можно освободиться от пут международно-правовых предписапий.

Причй такого курса США несколько. Не вдавалсь в их детальнуго характеристику, можно назвать глубокую запдеологизированность америкапцев (лозунги о деидеолопизации раньше выдвигали только применительно к бывшим государствам советского блока), когда па первое место, в том числе при определении внешнеполитических акций, выносятся американские идеалы, американский образ жнзни, по-американски трактуемые права человека. С этим же связано и явное стремление обеспечить гегемонистское положение США в мире вопреки требованиям международного права, в принципе запрещагощего гегемонизм. В своей внешней политике американцы исходят также в первую очередь из потребностей своей экономики, обеспечивая ее стабильное функционирование, лежащее в основе руководящей роли CIUA в мировых делах.

$\mathrm{K}$ сожалению, на мехдународном уровне существовавшие ранее сдерживания и противовесы американским внешнеполитическим акциям оказались в результате перемен близкими к нулю, и США удалось по многи направлениям серьезно подорвать международный правопорядок, часто при непротивлении или даже содействии международного сообщества и не в последнюю очередь международпцх организацнй.

Примеров таких действий США мпого. Остановимся лишь на главнейших из них.

По существу, отказавшись от выполнения свонх международных обязательств, СШUА задолжали гррмадные суммы в ООН. Затем, 
несколько изменив тактику, они сделали вопрос о погашенин своего долга предметом торговли с ООН, добиваясь в ответ на это провсдения в этой универсальной организации измененнй в желательном для них направлении. Американцы по-прежнему, поучая всех и каждого на тему о правах человека, не выполняют своих международных обязательств и не представляют доклады в этой области по уже ратифицированным универсальньм конвенциям.

Серьезную угрозу международному правопорядку несет практикуемое американцами при ратификации международных договоров формулирование оговорок, вряд ли совместимых с их объектом и целями. Такие оговорки были сделаны СШША при ратификацин, например, Международной конвенции о ликвидации всех форм расовой дискриминации, а также Международного пакта о граждапских и политических правах.

Однако, наверное, наиболес тяжелый урон международпому правопорядку наносит политика "санкций", проводимая США. Характеру подлинных санкций по современному международиолу праву отвечагт лишь коллективные меры, предусмотренные в соотвстствии с главой VII Устава ООН в случае существования угрозы миру, нарушения мира или акта агрессин. Такне меры прнинмались, например, Советом Безопасности ООН против расістских режимов. Американцы, самовольно наделяя себя правами Совета Безопасіости, с одной стороны, проводят под видом санкций по суцеству односторонние карателыные меры против ряда государств, которые являются откровенио противоправиыми. С другой же стороны, используя геополитическуго обстановку, им удавалось проводить неправомерные решения о принудительных мерах против тех или ниых государств через органы ООН, и прежде всего через Совет Безопасности, и, к сожалению, порой без противодействия России. Очевидиьм в этом. смысле было решение о направлении войск на Гаити со ссылкой на главу VII Устава ООН. В том же ряду стояло решение о расширении зоны воздушного патрулирования в Ираке со ссьлкой на ст. 51, в которой речь идет о самообороне в ответ на вроруженное нападение, чего Ирак определенно не делал.

При протаскивании решения об интервенции против Панамы американцы делали в свое время упор на то, что глава страны Норьега занимался, мол, наркобнзнесом (напомним для сравнения, что примерно в то же самое время причастньм $\mathbf{x}$ наркоделам оказался мэр Вашингтона. Как бы взглянули американцы на организацио интервенции против США на этом основании?). С другой же стороны, американцы и в этом, и другом случае использовалн аргументы гуманитарного характера, оправдываюоиие такое вмешательство. Например, организуя интервенцию против беззащитиой Гренады, США утверждали, что существовала якобы угроза американскнм студентам, обучавшимся в этой стране. 
Так называемые "гуманитарные" интервенции неоднократно предпрпппмались государствами в прошлом под знаменем спасения свонх граждап. Однако они допустимы, на наш взгляд, лишь при соблюдении нескольких вполне определеннцх условий. $\mathrm{K}$ их числу можно отнести необходимость их осуществления, то есть отсутствие возможности разрешить гуманитарную ситуацию другим способом, более соответствующим требованиям международного права, подлинно гуманитарные цели операций и их пропорциональность. Последние два условия означают, например, что недопустимо под предлогом оказания гуманитарной помощи свергать правительство страны.

И в аргументах политиков, и в выступлениях СМИ практически постолнгой является тема терроризма. Напомним, что терроризм имеет несколько основных форм. Террористические акты, к сожалению, вошли в жизнь многих стран, и против них применягтся соответствугшие меры на национальном уровне. На международном уровне осушествляотся захват заложников, угон самолетов и судов, пападение иа дипломатических агептов, тто наносит зиачтсльный ущерб правопорядку и в конечном счете касается всех страп. Против таких акций междупародное сообщество принимает меры, в том тисле путем выработки упиверсалыных конвенций.

Еще большуго опасность представляіот террористнческие акты междупаропиого характера, хогда $\mathrm{k}$ IIх осуществлешио причастиы те IлI Iпьс государства в лице своих организаций п представителей, однако н в нх отношении меры воздействия международного сообшества регламегтируются. Так, амернканцы с упорством организуют сапкцип в отношении Ливии в связи с террористическим актом против американского самолета над Шотландией в 1988 году. Однако если бы даже и было дохазано причастие ливийских властей $\mathrm{K}$ этому акту, то, хотя многосторонние конвенции 1970 и 1971 годов против незаконных актов в отношенин безопасности гражданской авиации и предусматривают ряд мер по борьбе с ними (уголовное преследование на национальном уровне, включение в договоры о выдаче и правовой помощи в связи с уголовно-процессуальными действиями, международное арбитражное разбирательство и разбирательство в Международном Суде), их юридическая квалификация как серьезных преступлений международного характера не предполагает применения $\mathrm{K}$ ним международных санкций.

Наибольший вред международному сообшеству наносят действия тех нли иных государств, берущих на свое вооружение террористические методы, в результате чего они превращаются в полномасштабные международные преступления, ставящие под угрозу международный мир и безопасность. Речь идет о государственном терроризме. Кменно в отношении таких международпых преступле- 
ний должны применяться все предписываемые международным правом меры принуждения.

Национально-освободительное движение, сторонники которого, конечно, должны соблюдать нормы международного права, и не в последнюю очередь гуманитарного, законы в области ведения военных действий, не стало, несмотря на все перемены в международных отношениях, явлением вчерашнего дня и продолжает действовать. Поэтому, когда, например, в комментариях СМИ по поводу событий на Ближнем Востоке одна сторона постоянно представляется в качестве регулярных, так сказать, цивилизованных войск, а другая в качестве если не террористов, то, по крайней мере, "боевиков", такая подача событий явно не отражает точку зрения международного права. Не следует забывать и того, что, хотя общепризнанного определения терроризма не существует, органы ООН в течение многих лет занимались этим вопросом, формулируемьм следующим образом: "Меры по предотвращению международного терроризма, который угрожает жизни невинных людей, или прнводит $\mathrm{x}$ их гибели, или ставит под угрозу основные свободы, и изучение коренных причин тех форм терроризма и актов насилия, которые проистекагт из нишеты, безысходности, бед и отчаяния и побуждают пекоторых людей жертвовать человеческими жизнями, включая II cвол coбственные, в стремленип добиться радикальных перемен".

Не оправдывая проявлений терроризма, международное сообщество, тем не менее, таким образом при характеристике этого сложнейшего явления побуждало не забывать и обстоятельства, которые вызывагот такие проявления.

По чьей-то воле или по неведению даваемая часто односторонняя трактовка многих явлений международной жизни характеризуется прежде всего замалчиванием мехдународно-правовой оценки этих ситуаций. Будь такая оценка дана, это, наверное, повлияло бы в значительной, если не решающей, степени на представления о них мировой общественности.

Так, последнее обострение обстановки на Ближнем Востоке, вызванное решением израильского правительства о создании новых еврейских поселений, обычно трактуется в качестве столкновения интересов изранльтян и арабов. Обходится молчанием тот факт, что для этой ситуации сушествует совершенно однозначная правовая оценка. Это решение представляет собой намерение изменить демографическую ситуацию на оккупированных территориях, оно абсолютно противоправно в свете категорического запрещения международным правом попыток оккупирующей стороны "перемещать часть своего собственного гражданского населения на оккупированную ею территорию". Такой запрет содержится в ст. 49 Женевской конвенции от 12 августа 1949 г. о защите гражданского населения во 
время войны. Поэтому меры по нарушению этого запрета должны рассматриваться в контехсте военных преступлений.

Следует особо сказать о роли международной юстиции.

Международиый Суд в Гааге зарекомендовал себя как подлинный орган международного правосудня. В 1984 году, например, он в ответ на действия США против Никарагуа, в частности минирование никарагуанских портов, вынес решение о прекращении такого минирования, а также решение, осуждающее какие-либо посягательства на суверенитет и политическую независимость Никарагуа с помощыю любых военных или полувоенных действий, а также угрозы силой. Вашингтон отказался тогда признать постановление Международного Суда*.

Практика деятельности же Международного трибунала по бывшей Югославии не свидетельствует о добросовестном выполнении им основной цели, поставленной при его создании Советом Безопасности в резолюции 827 от 25 мая 1993 г., - содействовать восстановлению и поддержанию мира.

В связи с югославской трагедией наибольшее внимание мирового сообщества было приковано к феномену этнических чисток.

Дать его точную правовую характеристику, определить его в терминах международного уголовного права - не просто, учитывая тот факт, что военные преступления и преступления против человечности имегот с ним много общего. Однако если многообразные военные преступления могут носить единичный характер, да и преступлегия против человечности, например геноцид, могут выражаться, скажем, в убийстве одного члена национальной и этнической группы, то этническая чистка уже по своему определению явление массовое. Поэтому выделение этнических чистох в особый состав позволило бы исклютить проявления предвзятости по отношению $\mathrm{K}$ лицам, совершавшим преступления на территории бывшей Югославии, преследовать именно тех из них, кто виновен в совершении этого массового преступления. Факты в отношении систематического применения этнических чисток могут быть установлены в цифpax жертв, которые им подверглись. Одной из самых первых массовых этнических чисток было массовое выдворение из Хорватии сербов, живших в ней в течение веков, а самым последним такого рода актом явилось изгнание нескольких десятков тысяч сербов из Сараево уже после подписания Дейтонских соглашений.

Однако такого выделения этнических чйсток в самостоятельный состав при разработке Устава Трибунала по бывшей Югославии сделано не было, хотя это и следовало из резолюций Совета Безопасности. Отсутствие же юридического определения этнических чисток дает возможность концентрировать внимание мировой об-

*International Court of Justice. Communique 84/18, May 10, 1984. 
щественности на привлечении $\mathbf{x}$ ответственности за еднничпые преступления, виновность за совершение которых трудно устапавливаемая, что и создает впечатлепие о причастности $\mathrm{k}$ преступления прежде всего представителей одной этнической группы, принимавшей участие в этой трагедии.

Не представляет также труда с точки зрения горидической техники обвинить в совершении тягчайших преступлений руководителей хорватов и боснийцев. Ведь индивидуальной ответственности за преступления в соответствии со ст. 7 Устава Международного трибунала подлежат лица, которые не только их совершили, но и планировали, подстрекали, приказывали или иньм образом содействовали или подстрекали $\mathbf{K}$ планированию, подготовке или их совершению. Однако этого судом сделано не было.

Создавая Трибунал, Совет Безопасности отнюдь не собирался передавать ему всю юрисдикциг в отношении судебного преследования лиц за серьезные нарушения международного гуманитариого права в бывшей Югославии. Уставом прямо предусматриваетсл участие в этом процессе и национальных судов.

Эта часть решения Совета Безопасности, однако, не получила никакого развития, а в результате одностороннсй ориентацин суда (а ведь по статусу судьи должны пролвлть беспристрастіость) в мировых СМИ практически ежедневно мелькают лишь сербские имена. Такая тенденциозная практика порочна и исклочительно опасна с точки зрения сохранения надежд па мнрнос развитие событий в этом взрывоопасном районе Европы.

Новые вопросы вызывает то, что (как показали действия западигков по аресту в начале июля 1997 года нескольких сербов, один из которых был убит) Трибунал ведет, так сказать, двойную бухгалтерию. Наряду с опубликованньм списком обвиняемых у него охазался другой, тайный список, о котором ничего не известно. Такие действия противоречат мандату Международных сил по стабилизацин, в частности Правилам процедуры и доказывания Трибунала, и уже привели к обострению обстановки в Боснии.

Можно поэтому с определенностью сказать, что деятельность Международного трибунала оставляет сомнения в его беспристрастности, что вряд ли способствует достижению поставленной Советом Безопасности цели.

Что может быть предпринято Россией в ответ на это явное умаление роли международного права в вопросах, представляюших первостепенное значение для мирового сообщества, ослабленне нового международного правопорядка, который начал в муках складываться благодаря усилиям большинства государств?

Прежде всего России, ее официальным представителям, ее обшественному мнению и СМИ следует осознать, что такая тенденция 
направлена против ее национальных интересов, интересов ее партнеров в различных райогах мира и что, напротив, усиление роли международного права и укрепление вследствие этого международного правопорядка отвечает в большинстве случаев этим интересам.

Следствием такого понимания должно стать неуклонное следование представителями России, и в первую очередь в ООН и ее главном органе - в Совете Безопасности, принципам и нормам международного права вопреки оказываемому на них давлению сил, заинтересованных в еще большем размывании правовых основ международных отношений.

Отношения с НАТО, российский федерализм, толкование принципа самоопределения, прежде всего применительно к Чечне, отношения с бывшіми республиками Советского Союза, в частности с Прибалтийскими странами (границы, положение русскоязыгного населсния), терроризм, права человека, гражданство (в том числе двойное), собьтил в ІОгославии (в том числе нақазание военных преступников), отношения с Китаем, Ираком, Ираном, Кубой - все это лишь часть проблем; которые должны рассматриваться с точки зрения международного права и интересов национальной безопасности России. Их международно-правовая проработка сделала бы российскис акции более результативными и пользуюшимися доверием международного сообщества.

Одновременно такая обоснованная с точхи зрения принципов и норм международного права позиция России подталкивала бы в какой-то степени и другие страны, и прежде всего CLUA, $\mathrm{K}$ отходу от нигиистического отиошени $\mathrm{x}$ международному праву, к соблюдению свонх международных обязательств и поддержанию международного правопорядка. Все это позволило бы внести большой вклад в поддержание международного престижа России и защиту ее национальных интересов.

Далее. Следовало бы усилить сотрудничество наших государственных органов, осуществляющих функцию поддержания внешних сношений страны, и прежде всего МИД России, с ученымимеждународниками в Дипакадемии, МГИМО, Институте государства и права и т.д. Должно стать правилом, что какие-либо более или менее важные внешнеполитические акции страны не могут осуществляться без их международно-правовой проработки на широкой межведомственной основе и при обязательном привлечении юристов-международников. Следует подумать над введением практики, имеющейся, по существу, во многих государствах мира, когда видиые дипломаты с правовым опытом командируются на определенпый период времени в высшие учебные заведения, а юристы-международники направлягося в дипломатические ведомства. Несколько лет назад при проведении научно-практических конференций в 
МИД одна из их секций занималась исклочительно правовыми вопросами. Затем от этой практики отказались, как бы подчеркивая соответствующее отношение $\mathbf{K}$ мехдународному праву. Следовало бы подумать о ее возобновлении.

Особо надо было бы проанализировать вопрос о том, что может быть сделано в направлении ориентации средств массовой информации об экспертной оценке с точки зрения как международного, так и внутреннего права главных событий, освещаемых ими. Если такая оценка будет оперативно делаться и доводиться до сведения СМИ, то соответственно будет сокращена возможность волюнтаристского в правовом плане их освещения.

В одобренной 7 мая 1997 г. на заседании Совета Безопасности России концепции национальной безопасности Российской Федерации говорится: "Национальные интересы Российской Федерации в международной сфере требуют проведения активного внешнеполитического курса на обеспечение важнейших националыых иитересов, упрочения позиций России ках великой державы - одного из влиятельных центров формирующегося многополярного мира". Опора на мехдународное право при выполнении этой задачи будет для России исключительно полезной.

г. Рейкьявик

Статья поступила в редахцию с сентабре 1997 а. 